\title{
On Translation Strategies of English Movie Titles
}

\author{
Zhihong Bai \\ Shanxi Normal University, Linfen, China
}

\begin{abstract}
Movie titles are films' eyes, having double effect of art appreciation and commercial advertisement, and directly playing the role of guidance and promotion. Good film names could convey the films' content as well as arouse audience's interest to get great box. With the continuous development of international cultural exchanges, film begins to get the attention of every nation increasingly as an important media in cultural exchange. With the opening of the Chinese market, we have more and more English movies. The Chinese audiences need to understand the movie titles before they enjoy the movies. But due to different cultural traditions, contexts, customs and thinking modes between the western and eastern world, the choices of their film names embodies distinctive cultural features. Movie titles convey the story to the audience to attract them. This requires the translation of movie titles to be accurate and embody the commercial values. This paper analyzes the translation strategies of English movie titles and explores a new strategy according to previous research results and research methods. This paper introduces the definition of translation strategies and some features of English movie titles and functions. Then it describes the principles of English movie titles translation and points out the translation strategies of English film titles. It is hoped that the context can help people to realize the necessity of proper translation of English movie titles, and accordingly promote the development of films in international market.
\end{abstract}

Index Terms - English movie titles, translation strategies, definition, features

\section{INTRODUCTION}

Movie is not only an art but also merchandise. The Chinese market is becoming more and more open, and there are an increasing number of English films. The Chinese audiences have to understand the film titles before they watch the movies. Movie titles express the main idea to the audience to draw their attention. This requires the translation of movie titles to be precise and reflect the economic values. After the analysis of the traits and functions of film names, this paper studied the translation skills and the translation tenets of the English film name. The film name is a necessary part of the movie. A beautiful title can make an influence on adding the finishing touch, appealing to audience and giving the viewers enough food for the soul. Movie titles often not only reflect the main idea of movies but also attract the audience with concise and unfamiliar form. With the frequent interaction between the Chinese and foreign cultures, an increasing number of English movies have entered into the market of China. The film name is the first thing through which the viewers can know about the movie, so the translation of English film titles is very important. A perfect translation of the title can express the main thought of the movie and attract the audience's desire of going to the movie. This paper will introduce the translation tenets and strategies of English film title based on an analysis of the traits and roles of English movie names. Translating such simple film title is seemed as an easy thing, but it is not easy to translate well. Being graceful in style and affluent in emotion could not only appeal to the audience but also be pregnant, and it makes people think deep as an art. Hence, when translating the movie name, firstly we should get the main idea and form of the movie, and then we have to know the principles, master the skills and see through the expression. However, academic atmosphere is very dreary and disputes are always united in the movie title translation research. Many academic articles only handle film names translation in detailed skills, for instance, literal translation, free translation and transliteration. However, they ignore the influences of culture and its versatility in film name translation. Moreover, there is also a lack in the exploration in the translation process and valuation. Thus, this thesis probes into the movie title translation, and puts in more strategies on top of the movie title translation theories. And it's ultimate purpose is bringing normalization and diversification into the English film names translation.

\section{LITERATURE REVIEW}

Chapter two mainly introduces translation and the translation strategies of English movie titles, and describes the research situation at home and abroad.

\section{A. The Brief Introduction to Translation}

Translation is taking a language into another language, and make sure the article is smooth. Translation is a process that using a familiar way to express a strange definition.

\section{B. The Brief Introduction to Translation Strategies of English Movie Titles}

The translation of English film names is to make the audience better understand the title of the original film through the translator. Therefore, the basic role of English movie titles is to provide viewers with useful information contents. 
The translation strategies of English movie titles include literal translation, free translation and transliteration. It hopes that it can make an effective translation for the audience. The title can play a translation role in guiding the process of translation. The translator needs to be communicated to a certain extent and improve the respect for the original title.

\section{The Research Situation at Home and Abroad}

In the past several years, enormous improvements have been achieved through generations of professors. But it is far from satisfying because of the job's sophistication. It is not rare to see that different versions of names of the same film arouse annoying confusion to the public. For the sake of reaching this purpose, many ways have been employed to direct the movie name translation. But none of them has won superiority in this competition, this study really wishes can provide some help to later research.

Since there are few foreign talents master Chinese language and can flexibly apply it into the Chinese movie title translation, at present, the majority of the Chinese movie titles translation are translated by the domestic translation scholars. The foreign movie name translation is also completed by the domestic scholars. The foreign scholars study on the Chinese movie name translation is slightly less. In China, the movie title Translation studies formally started in the 1990s. The Chinese scholar He (2001) states the movie title translation should follow four principles of information, culture, aesthetic, commercial value. Her research mentions four most important factors should be taken in to consideration in the film title translation. Jin (2001) analysis the skills of Chinese movie title translation. In this paper, on this basis of the extensive collection of original English film title translation, he analyses and classifies English film title translation principles, methods and standards for the further discussion. These researches in focus on the movie title translation skills, methods and the factors should be taken into account in the film title translation. Wang (2007) thinks translation is a language transformation based on the original content, it is restricted by the readers' demand, the translators' translation purpose and the target language culture. And the translation must be consistent with the original text in the content, form, style and function" (p.28). Their researches emphasize that the title translation should be faithful to the original content.

In conclusion, the common characteristic of these researchers is that the translation method and principle is too macroscopic and indistinct, and lack of the reference value and classification of the translation process. So this paper will take the basis of the film title characteristic and translation influence factors to put forward the targeted translation strategy in detail.

\section{RESEARCH DESIGN}

This paper reference to former research findings and survey methods, analyze the translation strategies of English film names and find a new strategy, to provide the translation of English movie titles for a certain help. It includes research purpose and research methods and lists the content of this research.

\section{A. Research Purpose}

Films are getting more and more prevalent from last century. Among which, English films have a great many of audience at home. As a consequence, an elaborately-translated title would be essential to attract more people to watch the film. Translating the films' titles would be of vital importance to promote this cross-cultural communication. The main goal is provide some help to later research. When we employ the method of literal translation to translate some succinct and short English film names, the completed titles cannot introduce the story expressly and neatly and thus can not offer information and appeal to audience; more specifics have to be added to let them more exact.

\section{B. Research Methods}

Firstly, the research use the way of observation through mastery of content about topics, then use some data collection and collation to make the whole process of observation. Secondly, the survey uses the action research method, tries to translate all kinds of movies, which generalizes the problems. Then continue to explore and summarize, and aim to improve. Thirdly, the research use the literature method, through the classification of reading related literature (including audio, images, video, text and other symbols, with value and information value certain historical value, theoretical material), to draw general conclusions or find problems, find new ideas.

\section{Content of This Research}

As for content of this research, this thesis will firstly analyze the problems existing in English Film Title Translation, then describe the profile of English movie name and lastly put up with some kind of translation strategies of English movie translation. As for research approach, this paper will research the questions through analysis, description, and contrast. The resources are chiefly chosen from journals, books and the Internet. The English films chosen are either Oscar winners or well-known to Chinese audiences.

Through access to knowledge and documents and concerning majors, and according to their own knowledge and professional topics provided according to the thesis guidance teacher, the topic can determined. The essential content of the study will be elaborated. This article is divided into four chapters to introduce English movie titles translation strategies. The first chapter introduces the topic research with respect to the definition of translation strategies. The second chapter describes some features of English movie titles and functions. The third chapter introduces the principles 
of English movie titles translation. The fourth chapter points out English movie names translation strategies. Finally it goes on a summary. The main goal is provided some help to later research. Culture is an important element we ought to attach importance to in translation. Some English film titles include some culture which will make the audience completely confounded, some English film titles involve some English idioms and proverbs and sometimes there is no equal word to the English titles, or on some other cases, the folk adages in English film names may discover the Chinese idiom equivalence. We translator can make a bridge for them and offer the audience a better title. We can borrow and vary from the ancient Chinese culture. The poems, some renowned phrases, and some fictions are all we can employ.

\section{The RESEARCH INTO SOME RELATED ISSUES}

This part will introduce some characteristics of English movie titles, such as brevity quality, cultural quality, artistic quality and commercial quality. And lists some functions of them.

\section{A. The Characteristics of English Movie Titles}

The features of English film names make the film better. These characteristics embody the movie's main contents.

\section{Brevity Quality}

Movie titles are normally short and concise to be noticeable for people. English film names always involve just one or two key words. Many of them are brief and short. The names are brief and compact, but they bear real weight. The titles sum up the main idea of the film and the viewers can readily get the idea of the movie. Gladiator introduces a tale of a Roman general, and he was forced to be a gladiator, then he fights for his liberty and belief. Return to Me, this is a romantic love story, mainly introduce the misunderstanding between a couple, and in the end they make peace and become reconciled.

And because the intended addresses of film titles are the general public, the language ought to be fashionable and extensive. Many finger of speech, for instance, simile, metaphor and Oxymoron are used in the movie name to make them live. Therefore, they can grab the audience's attention, draw their curiosity and cause their operation. The whole features of the English film names will be approached from linguistic, artistic, cultural and economic respects as follows.

In a general way, English movie names are short, brief and succinct. A great many of movie titles use only one word, and they are always be nouns. They may be the main figure, the place or the time when the story takes place. For instance, Speed, Mummy, Titanic and so on. Beyond that, phrases are always very popular in the movie names. A lot of these are noun phrases, verb phrases and prepositional phrases.

\section{Cultural Quality}

The definition of culture is needful for translators. Translators ought to be bilingualism and be bicultural as well. Translation ideologists, anthropologists have given definitions about culture in accordance with different emphasis laid on different aspects of culture. Language is a portion of culture. The film as a part of culture, it inevitably reflects their personal characteristic. When translating the name of a film, we need to understand all kinds of languages and cultural settings.

One more thing should be pointed out is that in translation, it includes two types of culture. One is called Culture with a big $\mathrm{C}$, and the other is named culture with a small c. The former refers to the culture that the text as a whole reflects or entails. This kind of culture roots in the cultural entity of some society. The later is the cultural elements that imply in different levels of language. In this paper, cultural elements refer to the second one-culture with a small c. Therefore, emphasis will be put on the cultural elements that entail in language.

The notion of culture is very extensive and complicated. Movie is a supporter of culture, too, which makes the movie names ought to have a specific cultural exchange function. If you can not know a special cultural background, you may not be able to understand the theme which the movie title expresses. The film seven, it describes the seven catholic cultures. If you do not know about the culture of foreigners, it is difficult to get the theme of this movie only from the title.

\section{Artistic Quality}

The film is an art, and to have a purpose of well satisfying the audience's tastes, movie titles commonly possess the art features. Movie titles can attain its art features through a rational use of the trope. Whether the names have art features will affect the audience's estimation about the film. Using the art form to perform the image of the initial text, emotive and art beauty of language, it will bring the beauty of the production to the viewers.

\section{Commercial Quality}

The film title has to appeal to the audience and then earn much money. So the names ought to offer the viewers suspension, illusion and aesthetic emotion in order to trigger their appetite of going to movies. Movie is a variety of commodity, which means that it has great commercial nature. In the same way, the film titles have artistic quality, it is economic, too. Movie is merchandise. There is a title I Know What You Did Last Summer, people want to know what they did last summer. The film has made a great process because this name made a substantial contribution.

\section{B. The Functions of English Movie Titles}


Through the British translator Peter Newmark's(1982) idea, there are six functions of language. It includes expressive function, informative function, vocative function, aesthetic function, phatic function and metalingual function. The film name is a work of the translator's diligence; it can highly sum up the main idea of the film and deeply trigger the audience's appetite of going to movies. So this paper will detail the next three functions, which contains informative function, vocative function and aesthetic function.

\section{Informative Function}

The informative function means that film titles conclude the information about the idea of the film to the audience and make them understand the movie and the opinion better. The informative function is a primary function of film names and it is the most important function. The title Forrest Gump will tell a story about a person named Forrest Gump. Pearl Harbor will tell the audience that this is the old history and people will know that the story takes place in Pearl Harbor and it is related to World War II .

\section{Vocative Function}

We heard that everyone is curious, if we see something strange and fresh, we will feel excited. And we will take pleasure in learning and readily be affected. The vocative function is just to affect the audience's sentiments and improve their interests. And make the film to appeal to the audience and express the main thought of the film.

\section{Aesthetic Function}

Aesthetic function in order to emerge from the original text, the translation should emphasize restraint, and know about the deep content of the article. The translator should use the artist's ingenuity to treat the original film, to make a new artistic creation and bring audience enjoyment from the title. The aesthetic feeling is a primary element that attracts audience to decide whether they will go to a movie or not. The aesthetic function always happens in the romantic movies. Some titles of the traditional films have turned into the synonym of romantic, for example, Casablanca, Sleepless in Seattle. Emphasizing the exact words, it aims to realize the aesthetic value. It should be the choice of both the beautiful words and vivid expression. And the meaning must be creative.

\section{The Analysis of Translation Strategies of English Movie Titles}

This chapter presents four principles of translation of English movie titles including faithful value, aesthetic value, commercial value and artistic value. The translation strategies are important to the translation of English movie titles. It puts forward four types of translation strategies of English movie titles through analyzing some English movies in this part.

\section{A. The Principles of Translation of English Movie Titles}

There are four principles of translation of English movie titles including faithful value, aesthetic value, commercial value and artistic value.

\section{Faithful Value}

Faithful is the most basic standard of translation of film names. Not only the language, but the cultural knowledge and the functional characteristics should be faithful. This is the best translation of film names. Faithfulness means that the language should obey the initial word; the translator must complete the contents of the original movie accurately without any wrong change, distortion, omissions, deletions, or any phenomenon castration. It means that the express ought to be loyal. Translation is a process that reflects the style of the initial film through a deeper understanding. And after thinking the meaning of the initial film name, unmistakably grasp the whole movie connotation. The movie name must straightaway, compliant, translated. It must be intelligible in modern linguistic, there should not be dead-by-word translation, hard translation, language obscure, and the phenomenon of barrier, structural confusion and the unclear logic.

\section{Aesthetic Value}

Language as an art, besides those contents in translation, it also should pay attention to the construct of the text and the graceful, beautiful, generous of the language. It should really make a kind of beauty for audience to enjoy.

Both the form and the content of this paper embody the aesthetic value of English movie. Formally speaking, foreigners employing brief beauty language, while the Chinese attach importance to symmetrical and friendly language, especially those have strong performance, well-proportioned four-character musical phrases. The audience accustomed to the words, which has rich cultural style and linked meanings and enriched the connotation of titles. Such translations is romantic, attract the mind of the viewers. Therefore, the translation of movie titles should be able to highlight the beauty of the language on harmony.

\section{Commercial Value}

Movie is a kind of culture, and it is an economic artwork, the commercial factors need to be considered in the translation of the titles. This requires the translator to grasp the features of the target language culture and aesthetic temperament and interest and to cause its psychological identity, inspire aesthetic pleasure and desire to watch. The film contains much art form. It contains play, music and literature. It is a special point as a categorized mass culture. That is to say, it needs the audiences' consumption. So the translation of film names, naturally have a business color. With the great development of the movie field in recent years, the movie is not only merchandise, also owed to the culture communication. The introduction of western films, peculiarly the English films, brings the exotic culture to the Chinese 
audience. But in the meantime, the film is also a type of business product, and it isn't used for collection, it is used to show. The lack of audience of the film was a failure. Title actually like a salesman in advance of the movie, and the main task of him is to communicate with his potential consumer and to persuade them to consume. Of course, with what method is depending on the type of subject and the way used by translators. As a commercial film, you need to bring the audience a strong call for effect. The purpose of film titles is to highlight the content of the film and the audience, to improve the box office. Obviously, in the translation of movie names, translators should be based on the ultimate goal of film titles to select the appropriate translation methods.

\section{Focus on the Art of Title}

Translation will be regarded as an artwork, and the film is an art. A perfect translation must be a beautiful artistic task. Sample The Bridge of Madison County, this translation is considered as one of the best translated names. Firstly, it is a four-character utterance, which attract the viewers. Secondly, the figures in the title involve many senses. Alliteration and rhyme often appear in The English film names, resulting in a repeat of pronunciation and in order to product effect of art.

\section{B. The Types of Translation Strategies of English Movie Titles}

The translation strategies are important to the translation of English movie titles. Fan(1994) said "Translation can basically adopt literal translation, free translation, translation, literal translation, annotation and other methods, but it really takes a lot of effort to express it well" (p.75). There are four types of translation strategies of English movie titles in this part.

\section{Literal Translation}

The so-called literal translation is to point to keep the original text, and keep the original form in translation when conditions permit, particularly to maintain the original metaphor, image and local contents. The purpose of English movie title translation is to show the main idea of the film. If the film name suits the novel closely, literal translation is the best method to employ. The particularity of different nations has universality. In general, whatever peoples' race, color, nationality, their feelings are, their moral standard is same. They are parts of different folks, but their views of things are same in many ways. Most of the English film names are composed of some nouns or verb phrases and sum up the primary thought of the film, literal translation is suited in this case, because literal translation can not only keep the main story of the title, but also the language construction of the initial title.

The film title translation in general is divided into two kinds of circumstances. One kind of circumstance is the word order should be same. The other is to replace the initial word order. Some translations can be completely copied according to the English film titles. Generally speaking, the translated titles ought not to be sounding uncomfortable or unnatural and are capable of describing the story as same as the original English titles. These titles are readily received and remembered by the audience. For instance, the Human Stain, Wild Orchid, Roman Holidays and Dancing with Wolves. Film titles are mostly strong representational, live and brief. If the translator uses the literal translation, it can use the same expression to express the same meanings; also can make the equal influence.

\section{Free Translation}

Although the literal translation's effect is good, not all of the title is fit for literal translation. Due to differences in language and culture between east and west, some titles must adopt free translation strategy. The translation of the American film Gone with the Wind is using the method of the free translation. The novel Gone with the Wind belongs to the literal translation, the translation is loyal to the initial text, and this translation is fine. The difference between free translation and literal translation centralism manifests in the expression. In reality, a lot of titles involve many cultural meanings. Literal translation is difficult in reflecting the essence of the movie, the translators ought to analyze and understand the content, style, plot and even style to carried out the title on the basis of the creative process. In this way, it can show the traits of the original title, and realize its cultural, aesthetic, and economic value.

Because the national value orientation between east and west, there are many different aesthetic psychologies, cultural background, etc. in some cases, if the title is literal translation, may lose their true sense of the original name, may even produce some wrong associations, affecting film image in the mind of the audience. In this case, free translation, can be used to highlight the characteristics of the film, to inspire the audience's desire to appreciate the movies.

\section{Transliteration}

Transliteration is a way that translates an English movie title into another language according to the pronunciation. There are a number of English movies regard hero name or location as the title. This kind of title translation usually means transliteration. If the name has been known by the audience or has important historical value, or better able to convey the exotic amorous feelings, this method is employed. And if the foreign text language and cultural differences can bring the audience into foreign situation, this method is also used. For example, Jane Eyre, Tess, Chicago, Romeo and Juliet, Harry Potter and so on. Of course, not every western person, place names, historical stories are using this way. That is to say, there are some names of the title audiences are not familiar with or they do not make sense directly or they are easy to misleading, or they will be took ambiguous to the audience, these titles are what we should avoid, such as, Forrest Gump doesn't make any works, not to leave any impression to the audience if the title were his name, while its familiar translation Forrest Gump is much more interesting and reminiscent of classics of Lu Xun's the true story of $A h Q$. 


\section{Other Translation Strategies}

As person names, place names used in the title, the translator should first transliterate the familiar names, then add the appropriate word to the films, this method can better reflect the meaning of the film. Some titles, although will be translated on the foundation of the denotation, translation is still not very perfect. Then can use literal translation and free translation, namely, the translator could translate the title on the basis of the original appropriate adjustments and according to the raw content and style to add words or delete words, in order to make a better effect. Another method is compilation. As the famous American translation theorist Nida (1993) said "it is to make the best and most standard translation, and the translation should be equivalent with the initial title. And the functional equivalence is to make the target language viewers have a same feeling as the source language viewers in accept the story information"(p.83). The last method is the expansion of the translation. Some English film titles need to be increased some words in the translation to explain formerly. In order to achieve the fidelity of the initial movie, and consider the audience of the target language habits, this approach is the inflation of the translation.

\section{CONCLUSION}

Movie plays an important role both in people's daily lives and international economy. In short, film name translation is a very difficult work. As merchandise and an art, movie will still be well received by people. With the opening of the film market, there are an increasing number of chances to watch English films. Sun (2002) thinks "translation is a type of language symbols into another language symbols, it is a create activities"(p.69). Due to the different characteristics of the source language and target language and the cultural imparities of all ethnic groups, the title from one language into another language is not easy, but a re-creation. Wang (1998) argues "English film subtitle translation should achieve the state should be as far as possible to maintain the original film style, so that the domestic audience to experience English of the original cultural connotation and artistic heritage" (p.27). Movie title is the first thing that audience can obtain the primary idea through and it has four staple features. Brief and concentrated, cultural, artistic quality and commercial. And it has three functions. It includes informative, vocative and aesthetic. Different kinds of film names decide different translation strategies. After analyzing the features, functions of the film names, translators can use transliteration, literal translation, and free translation to give audience the best translation. In the translation of the name of the film, the translator must handle source language and target language and find the differences between the source language and the target language and national culture. The translator also should require the aesthetics ability of a film and their sensitivity to cross-cultural communication. It is supposed that using the appropriate translation skills to retain their cultural characteristics, try their best to give the people the ideal translation of film titles to appreciate.

During the translation of English movie titles, for the purpose of making an equal effect, the translator ought to always be well remembered principles of faithfulness, cultural awareness, combination of merchant and aesthetic quality, and artistic quality, employing appropriate translation strategies to attain suitable expressions, and to give the audience most correct information and help them appreciate the films. Translation is a bridge of intercultural exchange; it is not a language translation, but a cultural translation. So in the course of translation, the translator should not only master the denotation of the word, but also know about the cultural significance it expresses. For commercial, the translators have to offer a noticeable movie title to attract the viewers.

English movie name translation is a complex work, to make a good name, the translator should have strong language foundation of basic knowledge, the strong cultural background information and translation exercise. Translators should spare no effort to the title translation practice to find the regularity, the advantages and the disadvantages, then apply it to the English movie name translation, then make the translation of English film titles be better.

\section{REFERENCES}

[1] Eugene A. Nida. (1993). Language, Culture and Translating, Shanghai: Shanghai Foreign Language Education Press.

[2] Fan Zhongying. (1994).Practical Translation Course. Beijing: Foreign Language Education and Research Press.

[3] Peter Newmark. (1982). Approaches to Translation. U.K: Pergamon Press Ltd.

[4] Sun Zhanxiao. (2002).Chinese Translation Features and Translation Skills in Foreign Language Films. Journal of Henan vocational and Technical Teachers College, 1, 67-69.

[5] Wang Ning. (1998).Translation Studies in the Context of Cultural Studies. Foreign Language and Translation, 2, 27-28.

Zhihong Bai was born in Lvliang, China in 1993. She is studying for her Master's degree in linguistics in Shanxi Normal University, China.

She is currently a student in the school of Shanxi Normal University. Her research interests include translation and applied linguistics. 